\title{
PELANGGARAN PRINSIP GOOD CORPORATE GOVERNANCE DALAM PERBANKAN SEBAGAI BAGIAN DARI WHITE COLLAR CRIME
}

\author{
Ida Nurhayati ${ }^{1)}$ dan Elisabeth $Y$. Metekohy \\ Jurusan Akuntansi Politeknik Negeri Jakarta-Jl. Prof. Dr. G.A Siwabessy \\ Kampus Universitas Indonesia Depok 16425 \\ Email: ${ }^{1}$ ida.nurhayati@akuntansi.pnj.ac.id, ${ }^{2}$ lisayansye@yahoo.co.id
}

\begin{abstract}
Abstrak
Penelitian ini sebagai bagian kecil dari disertasi yang membahas tentang Kejahatan Perbankan Dalam Perspektif Kriminologi, dengan menggunakan pendekatan kualitatif. Teknik nalisa menggunakan sebagian dari dimensi perilaku kejahatan Clinard-Quinney, yang terdiri dari 2 (dua) dari 5 (lima) dimensi perilaku kejahatan. Pelanggaran prinsip Good Corporate Governance dalam perbankan merupakan salah satu bentuk dari white collar crime, seperti dikemukakan oleh Sutherland, karena ciri-ciri yang dikemukakan telah terpenuhi oleh para pelakunya. Peraturan Bank Indonesia Nomor 8/4/PBI/2006 Tentang Pelaksanaan Good Corporate Governance Bagi Bank Umum. Hasilnya, dalam rangka menghadapi kompleksnya risiko, untuk meningkatkan kinerja, melindungi kepentingan semua pihak yang terlibat dalam perbankan (stakeholders), kepatuhan terhadap perundang-undangan, serta nilai-nilai etika perbankan. Dalam keadaan seperti ini, hampir setiap bentuk kejahatan di dalam korporasi dapat terjadi. Eksekutif korporasi pada tataran tinggi dapat mengelak dari tanggung jawab dengan dalih bahwa cara-cara tidak sah dalam mencapai tujuan korporasi yang dirumuskan secara umum sudah merupakan sarana yang tersedia tanpa dapat dikendalikannya.
\end{abstract}

Kata kunci: Prinsip Good Corporate Governance, Perbankan, White Collar Crime

\section{PENDAHULUAN \\ Latar Belakang}

Berbagai isu yang berhubungan dengan Corporate Governance (CG) menjadi populer di Indonesia di penghujung abad ke-20, tepatnya setelah terjadinya krisis ekonomi dalam bulan Juni 1997. Isu CG semakin gempar setelah berbagai lembaga keuangan multilateral, seperti World Bank dan ADB mengungkap bahwa penyebab krisis keuangan yang melanda berbagai negara, terutama Asia, tak lain adalah buruknya pelaksanaan Corporate Govvernance. Indonesia telah mengalami krisis ekonomi disekitar tahun 1997/1998, sementara gerakan kearah pembenahan kondisi corporate governance baru dimulai tahun 1999 dengan dibentuknya Komisi Nasional Kebijakan Corporate Governance (KNKCG atau NCCG). Kemudian momen penting untuk menindaklanjuti konsep Corporate Governance di Indonesia adalah dengan tersusunnya sebuah pedoman Good
Corporate Governance (Indonesian Code) oleh NCCG dengan para pelaku bisnis di tahun 2001. Disusul pula dengan Peraturan BI Nomor 8/4/PBI/2006 tentang Pelaksanaan Good Corporate Governance bagi Bank Umum.

Peraturan Bank Indonesia Nomor 8/4/PBI/2006 tentang Pelaksanaan Good Corporate Governance bagi Bank Umum, dalam konsideran dinyatakan bahwa, a. dengan semakin kompleksnya risiko yang dihadapi bank, maka semakin meningkat pula kebutuhan praktek good corporate governance oleh perbankan; b. bahwa dalam rangka meningkatkan kinerja Bank, melindungi kepentingan stakeholders dan meningkatkan kepatuhan terhadap peraturan perundang-undangan yang berlaku serta nilai-nilai etika yang berlaku umum pada industri perbankan, diperlukan pelaksanaan good corporate governance menunjukkan bahwa Bank Indonesia memandang pentingnya pelaksanaan good 
corporate governance dalam rangka menghadapi kompleksnya risiko, untuk meningkatkan kinerja, melindungi kepentingan semua pihak yang terlibat dalam perbankan (stakeholders), kepatuhan terhadap perundang-undangan, serta nilainilai etika perbankan.

Pada intinya prinsip dasar GCG yang disusun terutama oleh OECD terdiri dari lima aspek yaitu:

1. Transparancy, dapat diartikan sebagai keterbukaan informasi, baik dalam proses pengambilan keputusan maupun dalam mengungkapkan informasi material dan relevan mengenai perusahaan.

2. Accountability, adalah kejelasan fungsi, struktur, sistem dan pertanggungjawaban organ perusahaan sehingga pengelolaan perusahaan terlaksana secara efektif.

3. Responsibility, pertanggungjawaban perusahaan adalah kesesuaian (kepatuhan) di dalam pengelolaan perusahaan terhadap prinsip korporasi yang sehat serta peraturan perundangan yang berlaku.

4. Independency, atau kemandirian adalah suatu keadaan dimana perusahaan dikelola secara profesional tanpa benturan kepentingan manapun yang tidak sesuai dengan peraturan perundang-undangan yang berlaku dan prinsip-prinsip korporasi yang sehat.

5. Fairness (kesetaraan dan kewajaran) yaitu pelakuan adil dan setara di dalam memenuhi hak-hak stakeholder yang timbul berdasarkan perjanjian serta peraturan perundang-undangan yang berlaku (Emirzon, 2006).

Dalam riset yang dilakukan Biro Riset Infobank (birI), kasus fraud yang terjadi di BPD tak lepas dari posisi bank tersebut sebagai bank yang saham mayoritasnya, dimiliki pemda baik tingkat provinsi maupun kabupaten/kota. Pemda sebagai shareholdermerasa berhak melakukan intervensi, terlebih setelah memberikan kompensasi berupa penempatan dana APBD dan pembiayaan proyek-proyek yang membuat BPD selalu berada di comfort zone.(Wiryosukarto, 2012).

Tabel 1. Kasus Dugaan Fraud tahun 2011

\begin{tabular}{|l|l|l|l|}
\hline \multicolumn{1}{|c|}{ BPD } & \multicolumn{1}{|c|}{ Kasus } & \multicolumn{1}{|c|}{ Nilai } & \multicolumn{1}{|c|}{ Pelaku } \\
\hline Bank Kaltim & Kredit Fiktif & $\begin{array}{l}\text { Rp2 } \\
\text { miliar }\end{array}$ & $\begin{array}{l}\text { Kacab UUS } \\
\text { Penyelia } \\
\text { Utama }\end{array}$ \\
\hline Bank Jateng & Kredit Fiktif & $\begin{array}{l}\text { Rp94 } \\
\text { miliar }\end{array}$ & $\begin{array}{l}\text { Staf Analis } \\
\text { Pejabat Pemda } \\
\text { Kacab UUS }\end{array}$ \\
\hline $\begin{array}{l}\text { Bank } \\
\text { Sulselbar }\end{array}$ & $\begin{array}{l}\text { Pencairan Kas } \\
\text { Pemda }\end{array}$ & $\begin{array}{l}\text { Rp367 } \\
\text { juta }\end{array}$ & $\begin{array}{l}\text { Oknum PNS } \\
\text { Pemkab } \\
\text { Mamuju }\end{array}$ \\
\hline
\end{tabular}

Infobank (2012): diolah dari berbagai sumber.

Bank Indonesia sebagai lembaga yang saat ini masih diberi tanggungjawab mengawasi bank tentunya harus serius mengambil langkah-langkah untuk mengatasi kejahatan perbankan khususnya pembobolan bank. Sebab bisnis perbankan adalah bisnis kepercayaan. Sebagian dananya berasal dari dana pihak ketiga (deposan) (Nugroho, 2011).

Dari uraian keadaan di atas, maka penulis terdorong untuk melakukan penelitian, dengan melihat kondisi konkritnya pelaksanaan prinsip good corporate governance dalam bisnis perbankan. Karena pelanggaran prinsip tersebut sebagai suatu kejahatan kerah putih atau white collar crime.

\section{Landasan Teori}

Prinsip Good corporate governance

Prinsip Good corporate governance tersebut sebagai pedoman etika dalam menyelenggarakan operasional perbankan, maka kejahatan yang terjadi dalam perbankan dengan berbagai modus operandinya, menjadi tidak sinkron dengan pemberlakuan peraturan BI tentang good corporate governance yang telah dicanangkan melalui Peraturan Bank Indonesia Nomor 8/4/PBI/2006 tentang Pelaksanaan Good Corporate Governance bagi Bank Umum.

Perbankan, sebagai salah satu bagian dari bisnis keuangan, yang bersandarkan kepada kepercayaan masyarakat atas pekerjaannya, dengan keahliannya dalam pengeloalaan keuangan masyarakat 
(nasabah). Kepercayaan tersebut seringkali menjadi sebuah moment yang disalahgunakan oleh semua yang terlibat dalam kegiatan operasional bank untuk menyurangi masyarakat (nasabah) dengan berbagai modus operandi yang dapat merugikan masyarakat/nasabahnya.

Fraud (kejahatan) pada sistem perbankan apabila berada pada kondisi integritas yang rendah, kontrol yang lemah, akuntabilitas yang rendah, dan tekanan yang tinggi, peluang seseorang menjadi tidak jujur akan makin besar. Berdasarkan teori fraud triangle (segitiga kecurangan), tekanan, kesempatan, dan rasionalisasi yang datang secara bersamaan akan memperbesar peluang terjadinya fraud. Tapi, jika salah satu saja dari elemen segitiga tersebut hilang, fraud tidak akan terjadi. Pada sisi bank, menghilangkan kesempatan terjadinya fraud adalah yang paling mungkin ditindak-lanjuti (Meliala, 1993). Apabila yang melakukan pelanggaran adalah orang didalam bank, sebagai pelanggar prinsip good corporate governance, maka hal itu dapat dikategorikan sebagai kejahatan kerah putih atau white collar crime.

\section{White Collar Crime}

Di dalam kajian-kajian kriminologi, konsepsi tentang pelaku kejahatan tidak hanya dilakukan oleh orang-orang yang status sosial ekonominya rendah, tetapi juga dapat dilakukan oleh orang-orang yang terhormat, yang status sosial yang tinggi serta kedudukannya yang tinggi dalam pekerjaannya.

Kejahatan, pelanggaran/fraud di bidang perbankan, yang dilakukan oleh bankir sebagai individu maupun bank itu sendiri sebagai korporasi, keduanya dapat dikategorikan kejahatan kerah putih atau White Collar Crime, karena ciri-ciri dari pelaku White Collar Crime tersebut dapat kita jumpai disana. Kejahatan Kerah Putih (White Collar Crime ), dimana sejarah kelahiran model kejahatan ini dimulai oleh Edward ARoss ( 1806-1951 ) dan kemudian dipopulerkan oleh E.H.
Sutherland ( 1883-1950 ). Ia menegaskan bahwa KKP merupakan " the upperworld counterparts of the professional thieves " betapa pentingnya KKP dalam pandangan Sutherland sehingga dihadapan perkumpulan masyarakat sosiologi Amerika Serikat pada tahun1939 ia menegaskan sebagai berikut :

" The conventional explanations ( of crime, pen ) are invalid principally because they are derived from biased samples. The sample are biased in that they have not included vast areas of criminal behavior of persons not in the lower class. One of these neglected area is the criminal behavior of business and professional men " ( Atmasasmita, 1995).

"Penjelasan tentang kejahatan konvensional tidak valid, karena mereka berasal dari sampel yang bias, yang tidak memasukkan orang-orang kelas atas, yaitu pelaku bisnis dan orangorang profesional"

Sutherland dalam temuan dan usulannya, menyatakan pelanggaran hukum dalam kategori white collar crime sebagai kejahatan, terkait dengan pengertian kejahatan yang dianut dalam kriminologi yang berbasis sosiologi yaitu bahwa kejahatan tidak semata-mata pelanggaran hukum pidana, tetapi juga tindakan-tindakan lain yang walaupun tidak dilarang dalam hukum pidana atau tidak diancam dengan sanksi pidana, namun tindakan tersebut sangat merugikan masyarakat. Dari konsep tersebutlah kriminologi terus mengembangkannya yaitu dengan adanya corporate crime (kejahatan oleh perusahaan) (Mustofa, 2010)

Sutherland, ketika memperkenalkan konsep white collar crime, lebih fokus pada tipe pelaku yaitu orang-orang terhormat dengan ciri kelas sosial ekonomi tinggi, dengan menggunakan istilah whitecollar criminal. Namun dalam usahanya menjelaskan tipe pelaku kejahatan kelas atas tersebut, yang dianalisis oleh Sutherland adalah korporasi. Ketidak 
konsistenan Sutherland tersebut, justru membawa perkembangan kajian white collar crime, yaitu adanya kategori occupational crime dan corporate crime.
Dari kedua kategori dasar tersebut, berkembang menjadi kategori-kategori yang lebih kompleks. Seperti dalam skema berikut ini (Mustofa, 2010)

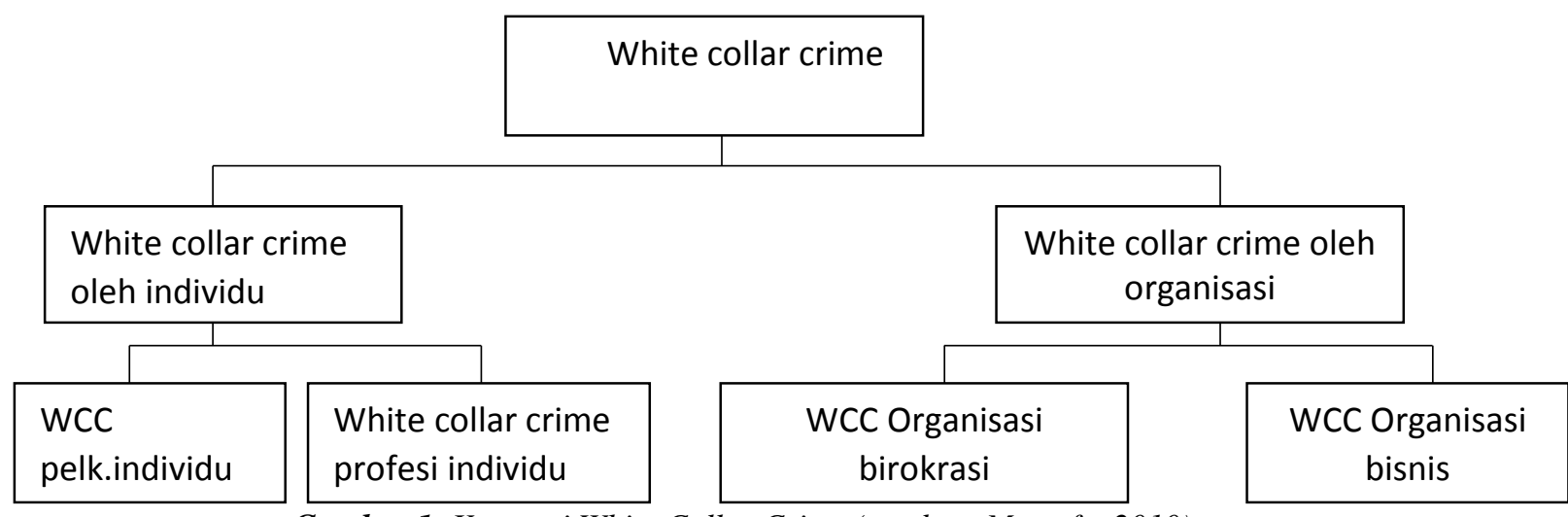

Gambar 1. Kategori White Collar Crime (sumber: Mustofa, 2010)

Berdasarkan skema tersebut dapat dijelaskan bahwa:

a. Semula konsep dasar white collar crime mengandung dua unsur utama, yaitu pelakunya merupakan orang-orang yang berstatus sosial ekonomi tinggi, dan kedua pelanggarannya dilakukan dalam kaitan dengan pekerjaannya atau jabatannya.

b. Pelanggaran dalam konteks konsep dasar white collar crime dapat dilakukan semata-mata berkaitan dengan pekerjaan seseorang secara individual, namun disisi lain pelanggaran tersebut dapat dilakukan oleh suatu organisasi.

c. Pelanggaran yang dilakukan oleh individu dapat merupakan pelanggaran yang dilakukan oleh pegawai dalam sektor swasta (private) dapat juga dalam sektor publik (birokrasi).

d. Dalam pelanggaran yang dilakukan berkaitan dengan kegiatan sah organisasi, pelanggaran tersebut dapat dilakukan oleh suatu badan usaha (korporasi) dapat juga oleh lembagalembaga pemeritahan.

e. Pelanggaran terkait dengan pekerjaan individu, dapat pula dengan profesi seseorang (dokter, pengacara, bankir tersmasuk didalamnya, dan sebagainya) namun dapat juga dilakukan oleh individu tidak terkait dengan jabatan profesional.

f. Cyber crime, terutama untuk transaksi e-banking, teknologi informasi yang demikian tidak semua anggota masyarakat memahaminya, dapat disalahgunakan untuk merugikan orang lain, secara individual maupun sebagai bagian dari kegiatan organisasi pemerintah maupun badan usaha (Mustofa, 2010).

Kejahatan kerah putih adalah sebuah konsep yang luas yang mencakup ilegal yang mengambil keuntungan dari posisi otoritas profesional dan kekuasaan dan struktur peluang yang tersedia dalam bisnis untuk keuntungan pribadi dan perusahaan (Kempa, 2010).

Jika kejahatan kerah putih didefinisikan baik dari segi perspektif tersebut, maka kejahatan kerah putih memiliki karakteristik sebagai berikut:

a. Kejahatan kerah putih merupakan kejahatan terhadap properti untuk keuntungan pribadi atau organisasi, yang dilakukan dengan cara non-fisik dan penyembunyian atau penipuan, pelanggaran kepercayaan dan mengakibatkan kerugian, hal ini disengaja.

b. Penjahat kerah putih adalah individuindividu, yang kaya, berpendidikan tinggi, dan terhubung secara sosial dan 
mereka biasanya dipekerjakan oleh dan dalam organisasi yang sah. Mereka adalah orang-orang terhormat dan status sosial yang tinggi yang melakukan kejahatan dalam proses pekerjaan mereka.

Kejahatan kerah putih adalah pelanggaran hukum yang dilakukan oleh orang yang memegang otoritas dan posisi terhormat yang menggunakan pekerjaan yang sah-nya untuk melakukan kejahatan keuangan (Eicher, 2009). Laura Snider (1993) senada yang disampaikan oleh Muladi (1992) mengemukakan tujuh macam karakteristik kejahatan orang-orang terhormat yang dalam hal ini termasuk dalam white collar crime: Pertama: kejahtan tersebut sulit dilihat (low visibility), karena biasanya tertutup oleh kegiatan pekerjaan normal yang rutin, melibatkan keahlian profesional. Disini perbankan sangat memungkin untuk terjadi seperti ini. Kedua, kejahatan tersebut sangat kompleks (complexity), karena selalu berkaitan dengan kebohongan, penipuan, dan pencurian serta seringkali berkaitan dengan sesuatu yang ilmiah, teknologis, finasial, legal, terorganisasikan, melibatkan banyak orang serta berjalan bertahun-tahun. Ketiga, terjadinya penyebaran tanggung jawab (diffusion of responsibility) yang semakin luas akibat kompleksitas organisasi. Keempat, penyebaran korban yang luas (diffusion of victimization) (Nitibaskara, 2006)

\section{Teknik Pengumpulan dan Analisa Data}

Penelitian ini menggunakan metode kualitatif, untuk mengetahui dan memberikan gambaran empirik tentang gejala yang terjadi di lapangan. Untuk memperoleh gambaran mengenai penerapan GCG di perbankan. Dan melihat perspektif pelanggarannya sebagai suatu kejahatan yang dapat dikategorikan sebagai white collar crime.

\section{METODE PENELITIAN}

Dalam memperoleh data yang dibutuhkan tersebut, maka akan melakukan beberapa tahap sebagai berikut :

Studi Pustaka :

Membaca buku-buku, jurnal ilmiah, artikel, data statisti kejahatan perbankan baik dari institusi resmi, Bareskrim maupun media cetak dan elektronik yang berhubungan dengan masalah kejahatan/pelanggaran perbankan.

\section{Teknik Analisis Data}

Teknik analisis yang digunakan adalah metode kualitatif :

1. Menganalisis hasil-hasil studi yang dilakukan sehubungan dengan pelaksanaan prinsip GCG dalam operasional bank.

2. Mengidentifikasi masalah/kasus-kasus perbankan untuk dilihat jenis, modus dan pelakunya.

3. Mengumpulkan informasi data sekunder dari sumber yang dapat dipercaya dari pihak-pihak yang berwenang dan terkait.

Penelitian ini menggunakan sebagian dari teknik analisa Clinard-Quinney yang dirujuk dalam Nurhayati (2015) yang menggambarkan, menelaah dan menjelaskan secara analitis prinsip Good Corporate Governance dan pelaksaksanaannya, diharapkan akan dapat diketahui bagaimana penerapan prinsip GCG tersebut dalam operasioanl perbankan. Apakah ada indikasi yang kuat atau lemah dengan penerapan prinsip GCG ataukah prinsip tersebut tidak berpengaruh terhadap munculnya/terjadinya kejahatan di bidang perbankan. Penelitian ini juga menggunakan data kepustakaan serta mencari data primer dan sekunder terdahap pemberlakuan prinsip GCG pada korporasi yang ada di bank-bank pemerintah dan daerah serta Bank Indonesia sebagai Bank Sentral yang bertindak sebagai pengawas perbankan di Indonesia. 


\section{HASIL DAN PEMBAHASAN}

Dari teori yang dikemukakan Sutherland (1939) sebagai pengguna pertama konsep white collar crime dalam analisisnya tentang white collar crime mengatakan bahwa korban-korban dari kejahatan yang dilakukan oleh korporasi bahwa pelanggaran-pelanggaran yang mereka lakukan bukan merupakan pelanggaran yang halus terhadap hukum, tetapi dilakukan dengan sengaja secara konsisten. Sutherland menyamakan karakteristik dari korporsai jahat dengan “ pencuri profesional ”, konsep dan karya lain dari Sutherland," The Professional Thief “ (1964) yang digunakan untuk menunjukkan bahwa teori asosiasi yang berbeda yang disusunnya mempunyai dukungan empiris.

Pertama, kejahatan yang dilakukan oleh korporasi seperti kejahatan yang dilakukan oleh pencuri yang profesional, bersifat menetap (aktivitas rutin). Sebagian besar dari pelaku adalah residivis, dalam arti melakukan pelanggaran lebih dari dua kali. Tidak ada upaya penindakan terhadap mereka yang mampu menghasilkan penjeraan.

Kedua, tindakan-tindakan pelanggaran yang dilakukan, baik oleh korporasi maupun pencuri profesional jauh lebih banyak dibandingkan dengan penghukuman atau penindakannya. Bahkan dalam dunia industri Sutherland menengarai bahwa hampir semua industri melakukan pelanggaran hukum.

Ketiga, para pelaku bisnis yang melanggar hukum yang dibuat untuk mengatur kegiatan bisnis, pada umumnya tidak kehilangan status dikalangan bisnis bila melakukan pelanggaran. Termasuk dalam kategori ini adalah pelaku bisnis yang dinyatakan bersalah oleh pengadilan, tidak pernah kehilangan reputasi dikalangan pebisnis lainnya.

Keempat, baik korporasi jahat maupun pencuri profesional sama-sama memandang remeh hukum yang berlaku, termasuk terhadap polisi, jaksa dan hakim. Mereka memandang remeh hukum karena menganggap bahwa hukum menghalangi kebebasan mereka (Wibowo, 2011)

Tabel 1. Dimensi Aspek Hukum Dan Etika Yang Dilanggar

\begin{tabular}{|c|c|c|c|c|c|}
\hline $\begin{array}{c}\text { Teori/ } \\
\text { Clinard- } \\
\text { Quinney }\end{array}$ & Kasus 1 & Kasus 2 & Kasus 3 & Kasus 4 & Kasus 5 \\
\hline $\begin{array}{l}\text { Perilaku } \\
\text { kejahatan yang } \\
\text { manusia } \\
\text { diciptakan oleh } \\
\text { agen yang } \\
\text { berwenang yang } \\
\text { terorganisir } \\
\text { secara politik } \\
\text { dalam suatu } \\
\text { masyarakat }\end{array}$ & $\begin{array}{l}\text { - Melaku-kan } \\
\text { pelanggaran } \\
\text { kode etik bankir, } \\
\text { prinsip } \\
\text { kepercayaan dan } \\
\text { kehati hatian } \\
\text { dalam } \\
\text { perbankan } \\
\text { - Melakukan } \\
\text { pelanggaran } \\
\text { Undang-Undang } \\
\text { Perbankan }\end{array}$ & $\begin{array}{l}\text { - Melakukan } \\
\text { pelanggaran } \\
\text { kode etik bankir } \\
\text { prinsip } \\
\text { kepercayaan dan } \\
\text { kehati hatian } \\
\text { dalam } \\
\text { perbankan } \\
\text { - Melakukan } \\
\text { pelanggaran } \\
\text { Undang-Undang } \\
\text { Perbankan }\end{array}$ & $\begin{array}{l}\text { - Melakukan } \\
\text { pelanggaran } \\
\text { kode etik } \\
\text { bankir prinsip } \\
\text { kepercayaan } \\
\text { dan kehati } \\
\text { hatian dalam } \\
\text { perbankan } \\
\text { - Melakukan } \\
\text { pelanggaran } \\
\text { Undang- } \\
\text { Undang } \\
\text { Tindak Pidana } \\
\text { Korupsi }\end{array}$ & $\begin{array}{l}\text { - Melakukan } \\
\text { pelanggaran } \\
\text { kode etik } \\
\text { bankir prinsip } \\
\text { kepercayaan } \\
\text { dan kehati } \\
\text { hatian dalam } \\
\text { perbankan } \\
\text { - Melakukan } \\
\text { pelanggaran } \\
\text { ketentuan } \\
\text { Undang- } \\
\text { Undang } \\
\text { Pencucian } \\
\text { Uang } \\
\end{array}$ & $\begin{array}{l}\text { - Melakukan } \\
\text { pelanggaran } \\
\text { kode etik } \\
\text { bankir prinsip } \\
\text { kepercayaan } \\
\text { dan kehati } \\
\text { hatian dalam } \\
\text { perbankan } \\
\text { - Melakukan } \\
\text { pelanggaran } \\
\text { Undang- } \\
\text { Undang } \\
\text { Perbankan }\end{array}$ \\
\hline
\end{tabular}

Sumber: diolah 2017 
Tabel 2 Dimensi Karir Pelaku Kejahatan

\begin{tabular}{|c|c|c|c|c|c|}
\hline $\begin{array}{l}\text { Teori/ } \\
\text { Clinard- } \\
\text { Quinney }\end{array}$ & Kasus 1 & Kasus 2 & Kasus 3 & Kasus 4 & Kasus 5 \\
\hline $\begin{array}{l}\text { Perilaku pelaku } \\
\text { dibentuk oleh } \\
\text { seberapa jauh } \\
\text { norma-norma dan } \\
\text { kegiatan yang } \\
\text { ditetapkan yang } \\
\text { menjadi bagian } \\
\text { dari } \\
\text { perkembangan } \\
\text { kejahatannya. } \\
\text { Perkembangan } \\
\text { peran sosial } \\
\text { pelaku, termasuk } \\
\text { peran dia } \\
\text { bermain, } \\
\text { identifikasi } \\
\text { perkembangan } \\
\text { kejahatannya } \\
\text { dengan penjahat }\end{array}$ & $\begin{array}{l}\text { - Pelaku baru } \\
\text { pertama kali } \\
\text { melakukan } \\
\text { pelanggaran dan } \\
\text { kejahtan yang } \\
\text { berhubungan } \\
\text { dengan } \\
\text { pekerjaannya } \\
\text { - Sebagai } \\
\text { bawahan yang } \\
\text { diperintahkan } \\
\text { oleh atasan } \\
\text { untuk } \\
\text { melakukan } \\
\text { pelanggaran. } \\
\text { - Sebagai bentuk } \\
\text { loyalitas kepada } \\
\text { pimpinan dan } \\
\text { institusi. }\end{array}$ & $\begin{array}{l}\text { - Pelaku baru } \\
\text { pertama kali } \\
\text { melakukan } \\
\text { pelanggaran dan } \\
\text { kejahtan yang } \\
\text { berhubungan } \\
\text { dengan } \\
\text { pekerjaannya } \\
\text { - Telah cukup } \\
\text { lama menangani } \\
\text { bagian kredit } \\
\text { pegawai yang } \\
\text { bekerja sama } \\
\text { denga pihak luar } \\
\text { yaitu pemda. }\end{array}$ & $\begin{array}{l}\text { - Pelaku baru } \\
\text { pertama kali } \\
\text { melakukan } \\
\text { pelanggaran } \\
\text { dan kejahtan } \\
\text { yang } \\
\text { berhubungan } \\
\text { dengan } \\
\text { pekerjaannya } \\
\text { Telah cukup } \\
\text { lama } \\
\text { menangani } \\
\text { bagian kredit } \\
\text { dan selalu } \\
\text { sukses. } \\
\text { Baru kali ini } \\
\text { melakukan } \\
\text { kesalahan dan } \\
\text { diketahui oleh } \\
\text { auditor dan } \\
\text { pimpinan }\end{array}$ & $\begin{array}{l}\text { - Pelaku baru } \\
\text { pertama kali } \\
\text { melakukan } \\
\text { pelanggaran } \\
\text { dan kejahtan } \\
\text { yang } \\
\text { berhubungan } \\
\text { dengan } \\
\text { pekerjaannya } \\
\text { - Mempunyai } \\
\text { hubungan yang } \\
\text { sangat dekat } \\
\text { dan baik denga } \\
\text { para } \\
\text { nasabahnya. } \\
\text { - Penampilan } \\
\text { dan } \\
\text { pergaulannya } \\
\text { yang tidak } \\
\text { umum }\end{array}$ & $\begin{array}{l}\text { - Pelaku baru } \\
\text { pertama kali } \\
\text { melakukan } \\
\text { pelanggaran } \\
\text { dan kejahtan } \\
\text { yang } \\
\text { berhubungan } \\
\text { dengan } \\
\text { pekerjaannya } \\
\text { - Mempunyai } \\
\text { pengalaman di } \\
\text { bank asing } \\
\text { - Berpendidikan } \\
\text { dari luar } \\
\text { negeri. } \\
\text { - Mempunyai } \\
\text { hubungan yang } \\
\text { sangat baik } \\
\text { dan dekat } \\
\text { denga para } \\
\text { nasabah yang } \\
\text { menjadi } \\
\text { korbannya }\end{array}$ \\
\hline
\end{tabular}

Sumber: diolah 2017

\section{KESIMPULAN DAN SARAN Kesimpulan}

Prinsip good corporate governance sebagai salah satu upaya Bank Indonesia untuk dapat meningkatkan kepercayaan masyarakat terhadap kinerja perbankan, khususnya di Indonesia. Pelanggaran dalam bidang perbankan termasuk dalam white collar crime, karena para pelaku sebagain besar adalah orang dalam, yang telah memiliki dan mengetahui teknis perbankan. Hal itu adalah ciri khas dari white collar crime, yang merupakan kejahatan yang berhubungan dengan pekerjaan, dilakukan oleh mereka yang mempunyai status sosial tinggi di masyarakat, serta berpendidikan.

\section{Saran}

Untuk mencapai pada idealnya good corporate governance pada dunia perbankan, hingga dapat dikurangi penyelewengan atau pelanggaran, semua pihak-pihak yang terkait harus bekerja sama dengan melakukan koordinasi antar bagian, serat kontrol yang kuat dari dalam oleh manajemen.
Prinsip good corporate governance tidak semata-mata untuk meningkatkan image atau kepercayaan masyarakat terhadap bisnis perbankan. Lebih dari itu agar dapat mencegah atau mengurangi kejahatan di bidang perbankan yang sangat merugikan masyarakat terutama para nasabahnya.

\section{DAFTAR PUSTAKA}

Abdullah, P. (2010, Oktober). Kejahatan Perbankan Dan Efektivitas Pengawasan

Perbankan:Menggabungkan Teori Permainan Dan Analitical Network Process. Buletin Ekonomi Moneter dan Perbankan .

Arinto Tri Wibowo, H. B. (2011, Mei Rabu). BI Godok Aturan Anti Kejahatan Perbankan. pp. 1-2.

Atmasasmita, R. (1995). Kapita Selekta Hukum Pidana Dan Kriminologi. Bandung: Mandar Maju.

Dermawan, M. K. (2009). Telusuran Teoritis Pembenaran Pencegahan Kejahatan Berpendekatan Sosial. 
Bunga Rampai Kriminologi , 107. Departemen Kriminologi Fakultas Ilmu Sosial Dan Ilmu Politik. Universitas Indonesia

Meliala, A. (1993). Menyingkap Kejahatan Kerah Putih. Jakarta: Pustaka Sinar Harapan.

Mustofa, M. (2010). KleptokrasiPersekongkolan Birokrat-Korporat Sebagai Pola White Collar Crime di Indonesia. Jakarta: Kencana Prenada Media Group.

Nitibaskara, T. R. (2001). Ketika Kejahatan Berdaulat. Jakarta: Peradaban.

Soelistianingsih, L. (2011). Kejahatan Bank: Bagaimana Melindungi Nasabah. Jurnal

Croall, Hazel. Understanding White Collar Crime. BuckinghamPhiladephia: Open University Press, 2001.

Hongming, Cheng, and Ma Ling. "White Collar Crime And The Criminal Justice System: Goverment Response To Bank Fraud And Corruption in

China." Journal of Financial Crime, 2009: 166-173.

Lukviarman, Niki. "Etika Bisnis Tak Berjalan Di Indonesia: Ada Apa Dalam Corporate Governance?" Jurnal Siasat Bisnis, 2004: 139-156.
Mustofa, Muhammad. Kriminologi-Edisi Kedua. Bekasi: Sari Ilmu Pratama, 2010

Quinney, Marshal B Clinard and Richard. Criminal Behavior System A Typology. Chapel Hill, Nort Carolina: Madison, Wisconsin, 1972.

SBM, Nugroho. "Mencegah Kejahatan Perbankan." Artikel, 2011.

Sitompul, Zulkarnain. "Memberantas Kejahatan Perbankan: Tantangan Pengawasan Bank." Jurnal Hukum Bisnis Vol 24-No 1, 2005.

Sumarwan, FR. "Mewaspadai Pembobolan Bank Melalui Transaksi L/C." Jurnal Hukum Bisnis, 2005: 27.

Wiryosukarto, Darto. "Agar BPD Aman Dari Fraud." No. 396 Vol.XXXIV, Maret Rabu, 2012: 66-67. 